\title{
Potential of the marine diatom Halamphora coffeaeformis to simultaneously produce omega-3 fatty acids, chrysolaminarin and fucoxanthin in a raceway pond
}

\author{
Cecilia A. Popovich $^{\mathrm{a}, \mathrm{b}, *}$, María B. Faraoni ${ }^{\mathrm{c}}$, Alejandra Sequeira ${ }^{\mathrm{c}}$, Yasmín Daglio ${ }^{\mathrm{d}}$, \\ Lucas A. Martín ${ }^{\mathrm{a}}$, Ana M. Martínez ${ }^{\mathrm{c}}$, María C. Damiani ${ }^{\mathrm{a}}$, María C. Matulewicz ${ }^{\mathrm{d}, \mathrm{e}}$, \\ Patricia I. Leonardi ${ }^{\text {a }}$
}

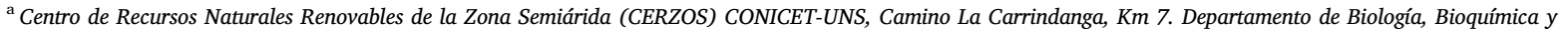
Farmacia. Universidad Nacional del Sur (UNS), San Juan 670, Bahía Blanca, Argentina

${ }^{\text {b } C e n t r o ~ d e ~ E m p r e n d e d o r i s m o ~ y ~ D e s a r r o l l o ~ T e r r i t o r i a l ~ S o s t e n i b l e ~(C E D E T S) ~ C I C-U P S O, ~ C i u d a d ~ d e ~ C a l i ~ 320, ~ B a h i ́ a ~ B l a n c a, ~ A r g e n t i n a ~}$

${ }^{\mathrm{c}}$ Instituto de Química del Sur (INQUISUR) CONICET-UNS, Departamento de Química. Universidad Nacional del Sur, Av. Alem 1253, 8000 Bahía Blanca, Argentina

${ }^{\mathrm{d}}$ CONICET-Universidad de Buenos Aires, Centro de Investigación en Hidratos de Carbono (CIHIDECAR), Ciudad Universitaria, 1428EGA Buenos Aires, Argentina

e Universidad de Buenos Aires, Facultad de Ciencias Exactas y Naturales, Departamento de Química Orgánica, Ciudad Universitaria-Pabellón 2, 1428EGA Buenos Aires, Argentina

\section{A R T I C L E I N F O}

\section{Keywords:}

Seawater

Fertilizer

Marine diatom

Eicosapentaenoic fatty acid

Chrysolaminarin

Fucoxanthin

\begin{abstract}
A B S T R A C T
Omega-3 eicosapentaenoic fatty acid (C20:5; EPA), $\beta$-glucan and fucoxanthin have received widespread attention owing to their potential industrial applications; however, their availability is currently limited to unsustainable sources such as fish oils and macroalgae. Though some species of diatoms are also a natural source of these metabolites, progress needs to be made in reducing the cost barriers involved in their large-scale production. The aim of the present study was therefore to assess the potential of the marine diatom Halamphora coffeaeformis to simultaneously accumulate EPA, chrysolaminarin and fucoxanthin in a raceway pond sustained by fertilizer $\left(\right.$ Bayfolan $^{\circledR}$ )-enriched seawater. The biomass production increased significantly along the experiment, the specific growth rate, biomass productivity and areal yield being 2.03 day $^{-1}, 0.128$ g.L $\mathrm{L}^{-} 1 . \mathrm{d}^{-1}$ and $25.73 \mathrm{~g} \cdot \mathrm{m}^{-2} \cdot \mathrm{d}^{-1}$, respectively. Proteins dominated in the first culture phase, while lipids, carbohydrates and pigments increased toward the end of the stationary phase. The harvested biomass presented $310 \mathrm{mg} . \mathrm{g}^{-1} \mathrm{DW}$ (dry weight) of total lipids containing high amounts of EPA ( $24 \%$ of total fatty acids), $114 \mathrm{mg} . \mathrm{g}^{-1} \mathrm{DW}$ of chrysolaminarin and $38 \mathrm{mg} \cdot \mathrm{g}^{-1} \mathrm{DW}$ of fucoxanthin. These values compare favorably with those obtained from commercially used sources. The culture medium proposed represents a non-conventional, cost-effective resource allowing for sustained high biomass levels throughout 22 days, guaranteeing the accumulation of valuable metabolites. Furthermore, the robustness and auto-flocculation capacity of the species increase the chances of viable scalability. These findings indicate the potential of H.coffeaeformis as a high-value metabolite feedstock, focusing on sustainable bioprocesses.
\end{abstract}

\section{Introduction}

Diatoms are unicellular photosynthetic eukaryote microalgae belonging to the Bacillariophyceae class. They have been studied for more than a hundred years owing to their key role in oxygenizing the earth's atmosphere and as one of the ocean's most important sources of biomass [1]. These microalgae dominate in mixed and rich nutrient waters, and most species have an obligate requirement for silicon (Si) to form their cell walls. Although variations exist, many marine diatoms have a relatively balanced nitrogen $(\mathrm{N}): \mathrm{Si}$ ratio within their biomass. Hence, changes in $\mathrm{N}$ and $\mathrm{Si}$ concentrations in the water will influence both the quantity (cell numbers and biomass) and quality (composition of this biomass) of a diatom population [2]. Regarding their biochemical composition, the chloroplasts are usually golden-brown, because the chlorophylls $a$ and $c$ are masked by the accessory pigment fucoxanthin. Chrysolaminarin is their main stored carbohydrate, a glucan that is

\footnotetext{
* Corresponding author at: Centro de Recursos Naturales Renovables de la Zona Semiárida (CERZOS) CONICET-UNS, Camino La Carrindanga, Km 7. Departamento de Biología, Bioquímica y Farmacia. Universidad Nacional del Sur (UNS), San Juan 670, Bahía Blanca, Argentina.

E-mail address: bmpopovi@criba.edu.ar (C.A. Popovich).
} 
accumulated outside the chloroplast under normal growth. They also store carbon in the form of triglycerides (TAG) under adverse environmental conditions. The major fatty acids of diatoms include C16:0 (palmitic acid) and C16:1 (palmitoleic acid), and polyunsaturated fatty acids (PUFA) such as C20:5u3 (eicosapentaenoic acid, EPA) and C20:4w6 (arachidonic acid, ARA) [3].

Diatoms have gained widespread attention in recent decades owing to their enormous commercial and industrial potential [4]. Industrial diatom cultures have been developed for the aquaculture industry [4] and other relevant commercial applications of diatoms at the small and semi-industrial scale are being investigated. Some of the significant advances include: (1) frustule studies for novel applications in nanotechnology, drug delivery and material science [5]; (2) EPA, chrysolaminarin and fucoxanthin production for application in aquaculture, food and pharmaceutical areas [6-8]; and (3) TAG production for biodiesel and other valuable co-products such as exopolysaccharides (EPS) [9-12]. Diatoms could currently be used for the development of various types of biorefineries [13]. For example, the potential market based on the combined production of EPA and fucoxanthin from $P$. tricornutum in hybrid raceway ponds was estimated in the billion dollar range by Leu and Bousiba [14]. However, the global microalgal market is currently dominated by other non-diatom species such as the Cyanophyta Spirulina and the Chlorophyta Chlorella, Dunaliella and Haematococcus [13].

Maintaining high biomass production is an important strategy to guarantee the production of high-value metabolites in diatoms on a commercial scale $[15,16]$. For production to be profitable, the costs associated with the cultivation units (i.e., photobioreactors or raceway ponds) and resources (i.e., nutrient and water resources) have to be brought down. EPA, chrysolaminarin and fucoxanthin content in diatom cells are species and strain specific, and they are also strongly affected by culture conditions [3] such as light intensity, salinity, nutrient concentrations and the balance between $\mathrm{N}$, phosphorus (P) and $\mathrm{Si}$ $(\mathrm{N} / \mathrm{P} / \mathrm{Si})$ in the medium. The aim of the present study was therefore to evaluate the potential of the marine and benthic diatom Halamphora coffeaeformis to accumulate EPA, chrysolaminarin and fucoxanthin in a raceway pond sustained by fertilizer (Bayfolan ${ }^{\circledR}$ )-enriched seawater. Fertilizer was selected to maximize biomass production due to its richness in nitrogen, phosphorus, vitamins and micronutrients, and for being an economically feasible culture medium at large scale. In addition, the dissolved and internal nutrient kinetics were investigated to gain insight into the nutritional behaviour of this species in a nonconventional culture medium. Previous studies $[11,12]$ have demonstrated the capacity of $H$. coffeaeformis to accumulate suitable TAG for biodiesel production under nutritional stress from a biorefinery approach. However, the potential of this species to simultaneously accumulate high-value compounds in a nutrient-rich raceway pond has not yet been studied and the studies that do exist on the simultaneous production of these valuable metabolites in diatoms grown in raceway ponds are of limited scope. The results of the present study are expected to contribute to the development of large-scale bioprocesses from marine benthic diatoms, focusing on sustainable high-value markets.

\section{Material and methods}

\subsection{Algal strain and laboratory scale-up}

Halamphora coffeaeformis (C. Agardh) Levkov was isolated from Bahía Blanca Estuary, Argentina, identified [11] and maintained in stock cultures in f/2 medium [17]. For small-scale culture (100 mL to $4 \mathrm{~L}$ ), cells from stock cultures were collected by auto-floculation and the supernatant was removed. The cells were then transferred to different flasks containing the selected medium consisting of seawater enriched with fertilizer $0.28 \mathrm{~mL} . \mathrm{L}^{-1}$ Bayfolan ${ }^{\circledR}$ to obtain $470 \mu \mathrm{M}$ nitrate $\left(\mathrm{NO}_{3}{ }^{-}\right)$, $700 \mu \mathrm{M}$ amonium $\left(\mathrm{NH}_{4}{ }^{+}\right)$and $100 \mu \mathrm{M}$ phosphate $\left(\mathrm{PO}_{4}{ }^{3-}, \mathrm{P}\right)$. The silicate $\left(\mathrm{SiO}_{4}{ }^{4-} ; \mathrm{Si}\right)$ was incorporated according to $5 \mathrm{f}$ medium (f medium
[17] with a $5 \times$ concentration of $\mathrm{Si}$ ) in order to obtain a ratio of $\mathrm{Si}: \mathrm{N} \sim 1$. TRIS buffer was incorporated according to $\mathrm{f} / 2$ [17]. At this stage of scale-up, aged seawater from Bahía Blanca Estuary with a salinity of $33 \%$ (ppt, parts per thousand) was filtered $(0.45 \mu \mathrm{m}$ Millipore) and autoclaved at $121{ }^{\circ} \mathrm{C}$ and $1 \mathrm{Atm}$ for $20 \mathrm{~min}$. Fertilizer, silicate and buffer were filtered ( $0.2 \mu \mathrm{m}$ Millipore) independently and then incorporated into sterilized seawater. The highest growth of $H$. coffeaeformis was obtained with $0.28 \mathrm{~mL} \cdot \mathrm{L}^{-1}$ Bayfolan $^{\circledR}$; growth was lower with concentrations of $0.1 \mathrm{~mL} . \mathrm{L}^{-1}$ and $0.38 \mathrm{~mL}^{-1} \mathrm{~L}^{-1}$ of Bayfolan ${ }^{\circledR}$ (data not shown). Four-day cultures (approximately $0.5 \times 10^{6}$ cells. $\mathrm{mL}^{-1}$ ) were used as inoculum at $10 \%$ volume in each scale-up step until reaching a $4 \mathrm{~L}$ cultivation flask, which was incubated for 7 days at $20{ }^{\circ} \mathrm{C}$ under continuous air bubbling (500-700 $\left.\mathrm{cm}^{3} \cdot \mathrm{min}^{-1}\right)$ containing $0.30 \mathrm{~cm}^{3} \cdot \mathrm{min}^{-1}$ of $\mathrm{CO}_{2}$.

\subsection{Scale-up of photobioreactor (PBR) to raceway pond}

A cylindrical borosilicate 25 L photobioreactor (FIGMAY S.R.L, Córdoba, Argentina) was used to obtain a 20 L-inoculum for a $300 \mathrm{~L}$ raceway pond, for which the $4 \mathrm{~L}$ cultivation flask was inoculated in the PBR and the culture was carried out over 7 days in a room at $20 \pm 2{ }^{\circ} \mathrm{C}$ with Bayfolan ${ }^{\circledast}$ medium (see Section 2.1). LED panels around the PBR provided $100 \mu \mathrm{mol} . \mathrm{m}^{-2} . \mathrm{s}^{-1}$ of light intensity under a cycle of $12: 12 \mathrm{~h}$ light/darkness. The culture was supplied with $1 \% \mathrm{CO}_{2}$ in air during $2 \mathrm{~h}$ and maintained under stirring by means of central paddles at $30 \mathrm{rpm}$. These conditions were selected with the dual aim of avoiding a significant decrease in $\mathrm{pH}$ and maintaining a moderate mixing regimen, taking into account the marine and benthic habits of the studied strain, respectively.

Finally, a PVC raceway pond of $2 \mathrm{~m}$ length, $0.5 \mathrm{~m}$ width and $0.3 \mathrm{~m}$ height was used to obtain a biomass rich in high-value products. The $20 \mathrm{~L}$ - inoculum from the PBR was incorporated in the $300 \mathrm{~L}$ raceway pond and the culture was carried out over 22 days in a greenhouse with natural light and temperature. The initial culture volumen was $220 \mathrm{~L}$ (200 L seawater with 0.28 mL.L $^{-1}$ Bayfolan $^{\circledR}+20$ L inoculum). The seawater was enriched with Bayfolan ${ }^{\circledR}$ fertilizer and silicate to obtain ratios of Si:N $\sim 1$ and $\mathrm{N}: \mathrm{P} \sim 16$ in accordance with the Redfield/ Brzezinski Si:N:P ratios of 16:16:1 [2]. Buffer TRIS was not incorporated. The stirring was produced by acrylic paddle wheels and turbulence provided by air-bubbling enriched with $1 \% \mathrm{CO}_{2}$. At this stage of scale-up, filtered ( $1 \mu \mathrm{m}$ Millipore) seawater (Bahía Blanca's Estuary, 33\%o) was sterilized with 5\% sodium hypochlorite and neutralized with 0.15 g.L $\mathrm{L}^{-1}$ sodium thiosulfate. Water temperature and $\mathrm{pH}$ were measured with $\mathrm{pH}$ meter (POCKET PRO pH TESTER, HACH), and salinity was measured daily in situ with a multiparameter digital meter CONSORT C562. The daily PAR was measured with a radiometer LICOR model LI-192SB at different times of day (from 6:00 A.M to 20:00 $\mathrm{P}: \mathrm{M})$. The biomass was harvested by scraping with a shovel, since this species autoflocculate and forms a biofilm on the bottom.

\subsection{Growth measurements and analytical methods}

\subsubsection{Growth rate and biomass determination}

Samples were taken daily in triplicate for cell density and biomass determination. Cell density ( $\mathrm{N}^{\circ}$ cell.mL ${ }^{-1}$ ) was determined by counting triplicate samples in a Sedgwick-Rafter chamber. The specific growth rate $(\mu)$ was calculated during the period of exponential growth by a least squares fit to a straight line of logarithmically transformed data, which were expressed as day ${ }^{-1}$. For biomass, duplicate samples of $20 \mathrm{~mL}$ were filtred through pre-conditioned and pre-weighed Whatman $\mathrm{GF} / \mathrm{C}$ filters $(1.2 \mu \mathrm{m})$. The filters containing the samples were then washed three times with $10 \mathrm{~mL}$ distilled water and dried in an oven at $60{ }^{\circ} \mathrm{C}$ for $24 \mathrm{~h}$, cooled in a desiccator and weighed until constant weight (DW). 


\subsubsection{Nutrient analyses}

Samples of $20 \mathrm{~mL}$ were taken daily, filtered through Whatman GF/F filters $(0.7 \mu \mathrm{m})$ and frozen at $-80{ }^{\circ} \mathrm{C}$ until analysis. The filtrate was used for dissolved nutrient determination, and the filters containing the cellular pellet were used for internal nitrate analysis. Internal nitrate was determined after extraction with boiling, distilled and deionized water [11]. The procedure was complemented with an Omni Sonic Ruptor 400 cell disruptor, exposing the samples to pulses of $30 \%$ power for $3 \mathrm{~min}$, using a $3 \mathrm{~mm}$ diameter tip. Nutrient concentrations were determined via colorimetric assays in order to measure phosphate $\left(\mathrm{PO}_{4}{ }^{3-}\right)$; amonium $\left(\mathrm{NH}_{4}{ }^{+}\right)$; nitrate $\left(\mathrm{NO}_{3}{ }^{-}\right.$, dissolved and internal) and silicate $\left(\mathrm{SiO}_{4}{ }^{4-}\right)$ [18]. Absorbances were measured with a Varian Cary $60 \mathrm{UV} /$ Vis Spectrophotometer (Agilent, USA) at $543 \mathrm{~nm}$ for $\mathrm{NO}_{3}{ }^{-}$, $630 \mathrm{~nm}$ for $\mathrm{NH}_{4}{ }^{+}, 885 \mathrm{~nm}$ for $\mathrm{PO}_{4}{ }^{3-}$ and $810 \mathrm{~nm}$ for $\mathrm{SiO}_{4}{ }^{4-}$. Dissolved nutrients were referenced as $\mu \mathrm{M}$ and internal nitrate concentrations were normalized to cell number (pg.cell ${ }^{-1}$ ). The standard ratios of $16 \mathrm{Si}: 16 \mathrm{~N}: 1 \mathrm{P}$ were used to evaluate the possible nutrient limitation. For this, dissolved inorganic nitrogen concentration (N) was calculated as the sum of dissolved $\mathrm{NO}_{3}{ }^{-}$and $\mathrm{NH}_{4}{ }^{+}$.

\subsubsection{Protein, carbohydrate and lipid content quantification}

Samples of $40 \mathrm{~mL}$ for biochemical composition were taken on selected days $(0,2,5,6,7,9,11,13,15,17,22)$ to cover different growth phases. Samples in triplicate were filtered through Whatman GF/C filters $(1.2 \mu \mathrm{m})$ and stored at $-80{ }^{\circ} \mathrm{C}$ until analysis. Proteins and carbohydrates were then spectrophotometrically determined using the Coomassie Brilliant Blue dye method [19] and the phenol-sulfuric acid assay [20], respectively. These methods are explained in more detail in Popovich et al. [21]. Lipids were determined according to Weldy and Huesemann [22].

\subsubsection{Fatty acid characterization}

The fatty acid methyl ester (FAME) profile of total lipid from biomass harvested on day 22 was determined and analyzed by gas chromatography with an HP Agilent 4890D gas chromatograph according to Popovich et al. [23]. FAME identification was performed by comparison with standard certified material, Supelco FAME $10 \mathrm{mix} 37$ (Bellefonte, PA, USA), according to AOCS Official Method Ce1b-89. Four replicates of each FAME analysis were done.

\subsubsection{Cell polysaccharide extraction and structural analysis}

Polysaccharides from biomass harvested on day 22 were analized. Cellular polysaccharides were extracted from freeze-dried cells of $H$. coffeaeformis $(9.4 \mathrm{~g})$ using water at room temperature by magnetic stirring at $300 \mathrm{rpm}$ for $2 \mathrm{~h}$ (product RTW). The supernatant was collected by centrifugation $(10,000 \times g$ for $30 \mathrm{~min})$, and the precipitate reextracted with hot water at $100{ }^{\circ} \mathrm{C}$ (product W100) for $2 \mathrm{~h}$. The extracts were dialyzed $(72 \mathrm{~h}, 3500$ MWCO; Spectrum laboratories, Pennsylvania, USA) and lyophilized (RTW: yield, 3.50 g; W100: yield, 1.52 g; Virtis Freezemobile 3, SP Scientific, Pennsylvania, USA).

For the structural analyses, W100 (22 mg) was methylated using powdered $\mathrm{NaOH}$ in dimethyl sulfoxide-iodomethane [24] containing $30 \mathrm{mg} \mathrm{LiCl}$. The permethylated polysaccharide was extracted with chloroform $(\times 4)$, the extracts were collected, and the solvent was evaporated under a current of dry air. All the chemicals were purchased from Sigma-Aldrich (USA).The yield after the second methylation step (W100-m) was $8.5 \mathrm{mg}$.

\subsubsection{Monosaccharide composition}

Monosaccharide composition was determined by gas-liquid chromatography (GLC) (Hewlett-Packard 5890A Gas Chromatograph, California, USA) after hydrolysis of the extraction products according to Daglio et al. [25]. When necessary, GLC-MS analyses were performed on a Shimadzu QP-5050A (Kyoto, Japan) apparatus working at $70 \mathrm{eV}$ using the same column and conditions described by Daglio et al. [25], but with helium as a gas carrier at a total flow rate of $1 \mathrm{~mL} \cdot \mathrm{min}^{-1}$; the injector temperature was $240{ }^{\circ} \mathrm{C}$.

\subsubsection{Nuclear magnetic resonance spectroscopy}

W100 extract $(20 \mathrm{mg}$ ) was dissolved in deuterated DMSO (0.5 mL) (Sigma-Aldrich, USA) using $5 \mathrm{~mm}$ tubes. Spectra were recorded at room temperature on a Bruker Avance II $500 \mathrm{MHz}$ spectrometer (Karlsruhe, Germany). For the $500 \mathrm{MHz}{ }^{1} \mathrm{H}$ NMR experiment, the parameters were: spectral width of $7.5 \mathrm{kHz}, 30^{\circ}$ pulse, acquisition time of $4.4 \mathrm{~s}$ and relaxation delay of $1 \mathrm{~s}$, for 64 scans. Signals were referenced to $2.50 \mathrm{ppm}$. The ${ }^{1} \mathrm{H}-{ }^{13} \mathrm{C}$ HSQC technique was supplied by the spectrometer manufacturer; spectra were recorded at room temperature and were obtained at a base frequency of $500 \mathrm{MHz}$ for ${ }^{1} \mathrm{H}$ and $125 \mathrm{MHz}$ for ${ }^{13} \mathrm{C}$.

\subsubsection{Fucoxanthin and chlorophyll a extraction and quantification}

For fucoxanthin (Fx) and chlorophyll $a$ (Chl $a$ ) determination, samples of $20 \mathrm{~mL}$ were taken on selected days $(0,2,5,6,7,9,11,13$, $15,17,21$ and 22) to cover different growth phases. Each sample was filtered through a Whatman GF/C filter $(1.2 \mu \mathrm{m})$ and stored at $-80{ }^{\circ} \mathrm{C}$ until analysis. The total carotenoid extraction procedure was optimized in line with an exhaustive bibliography search [6,26-28]. Filtered samples containing $H$. coffeaeformis cells in different culture stages were suspended in absolute ethanol (100\% HPLC grade, Supelco, USA) for pigment extraction (ethanol:alga culture filtered volume $=1: 6 ; \mathrm{v} / \mathrm{v}$ ). The ethanol:biomass dry weight (DW) ratio was 5:1 v/w. The whole extraction process was performed in the dark to prevent pigment breakage. Each extraction system was mixed by vortex for $1 \mathrm{~min}$ and incubated in a brown tube with a magnetic stirrer at $40{ }^{\circ} \mathrm{C}$ for $2 \mathrm{~h}$. Pigment ethanolic extracts were filtered through a $0.2-\mu \mathrm{m}$ PTFE syringe filter and placed in brown 2-mL HPLC auto sampler vials with Tefloncoated lids. Samples were analyzed with a LS-MS - Thermo Scientific UltiMate 3000 - MSQ PLUS HPLC system equipped with an AcclaimTM 120 - C18 reverse phase column ( $3 \mu \mathrm{m}$ particle size, $2.1 \mathrm{~mm} \times 150 \mathrm{~mm}$; Dionex Bonded Silica Products) and a fixed wavelength UV detector. Fucoxanthin was monitored at an absorbance of $445 \mathrm{~nm}$. For HPLC, a flow rate of $0.5 \mathrm{~mL} \cdot \mathrm{min}^{-1}$ of the mobile phase was controlled by binary pumps at $25{ }^{\circ} \mathrm{C}$. The mobile phase consisted of acetonitrile (Supelco, USA) and Milli-Q water. Water was purified by using a Milli-Q (Millipore, Billerica, MA) system, giving a product with a resistivity of $\sim 18.5 \mathrm{M} \Omega / \mathrm{cm}$. After loading the column with the pigment ethanolic extract, the mobile phase was programmed with an isocratic ratio 83:17 acetonitrile:water solution over $15 \mathrm{~min}$. Total injection time was $15 \mathrm{~min}$. Between each sample injection an absolute ethanol (100\%) blank was run. Using fucoxanthin analytical standard (Supelco, USA), an external calibration curve was constructed; the peak area with a retention time of $4.566 \mathrm{~min}$ was employed for quantification. Each ethanol volumetric standard concentration, in the range of 4-100 $\mu \mathrm{g} \cdot \mathrm{mL}^{-1}$, was determined by UV-Vis spectroscopy (Agilent Cary $60 \mathrm{UV}$-Vis spectrophotometer) with an E value $(0.1 \%, 1 \mathrm{~cm})$ of $160 \mathrm{~L} /$ $\mathrm{g} / \mathrm{cm}$ at $449 \mathrm{~nm}$ [29]. Based on this information, the Fx volumetric concentration (mg.L ${ }^{-1}$ ) and Fx content (mg.g ${ }^{-1}$ DW) in each sample were estimated.

Chl $a$ content was determined by UV-Vis spectrophotometric assay using Agilent Cary 60 UV-Vis spectrophotometer. For construction of the calibration curve, several dilutions of purified Chl $a$ solution (Sigma Aldrich, St. Louis, MO, USA) in acetone (HPLC grade) were prepared. Absorbance with an E value $(0.1 \%, 1 \mathrm{~cm})$ of $82 \mathrm{~L}^{-g^{-1}} . \mathrm{cm}^{-1}$ at $663 \mathrm{~nm}$ was used to calculate diluted concentrations in a range of $20-100 \mu \mathrm{g} \cdot \mathrm{mL}^{-1}$. The visible spectrum of pigment ethanolic extract in each culture stages was obtained by scanning from 300 to $800 \mathrm{~nm}$. The Chl $a$ volumetric concentration (mg. $\mathrm{L}^{-1}$ ) in each sample was estimated by substrating Fx to the total concentration value calculated at $663 \mathrm{~nm}$, which corresponded to Chl $a+$ Fx concentration [28].

\subsection{Statistical analysis}

The results are expressed as mean values \pm standard deviation 

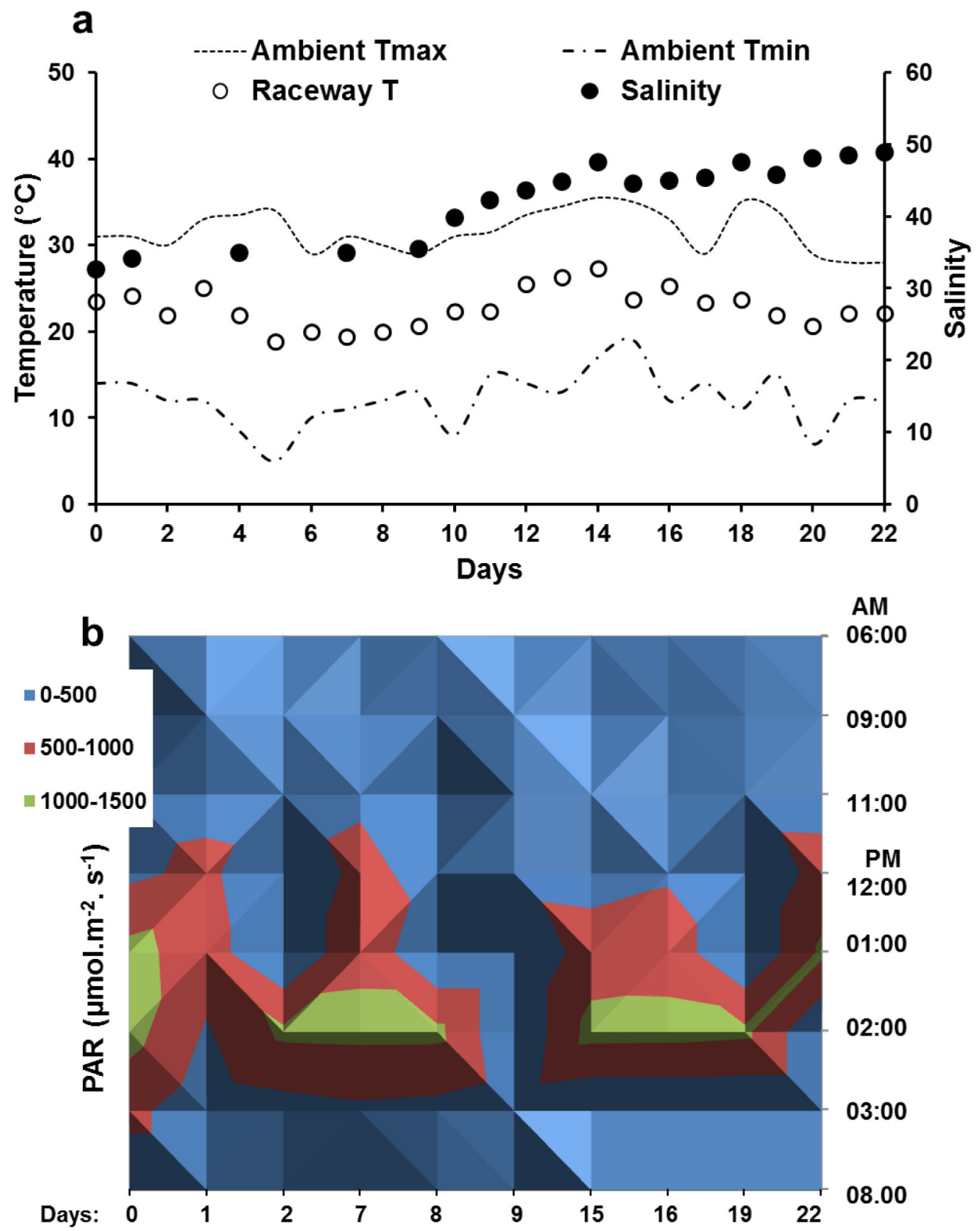

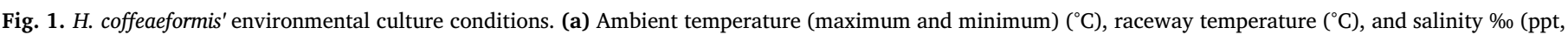
parts per thousand) throughout 22 days. (b) Incident PAR $\left(\mu \mathrm{mol} . \mathrm{m}^{-2} . \mathrm{s}^{-1}\right)$ at different daylight hours.

(SD). The differences in the mean values of the protein, carbohydrate and lipid contents $(n=3)$, as well as the fucoxanthin and chlorophyll volumetric concentration and content $(\mathrm{n}=3)$ throughout the experiment were evaluated with a paired student's $t$-test $(\alpha=0.05)$. In all cases, comparisons that showed $p<0.05$ were considered significant. Statistical analyses were performed using Infostat Software (version 2017.1.2).

\section{Results and discussion}

\subsection{Environmental conditions and biomass production}

The ambient temperature ranged from $5{ }^{\circ} \mathrm{C}$ to $35{ }^{\circ} \mathrm{C}$ and the water temperature varied between $18.8{ }^{\circ} \mathrm{C}$ and $27.3^{\circ} \mathrm{C}$ (Fig. 1a), indicating the good thermal balance produced by the movement of the paddle wheels. The water temperature values were within the range of conditions used for culturing microalgae in raceway ponds [30]. The salinity was increased gradually from $32.7 \%$ o to $35 \%$ until day 9 , and then increased considerably up to $47.9 \%$ on day 22 (Fig. 1a). The studied strain remained productive throughout the culture, an advantageous feature for its growth in open pond systems, where salinity can increase over time due to evaporation. In addition, the culture was exposed to varying intensities of natural PAR throughout the day, with maximum values ranging from $1000 \mu \mathrm{mol} . \mathrm{m}^{-2} . \mathrm{s}^{-1}$ to $1500 \mu \mathrm{mol} . \mathrm{m}^{-2} . \mathrm{s}^{-1}$ between $\sim 1: 00$ P.M. and $\sim 2: 30$ P.M. (Fig. 1b). Increasing incident irradiance levels generally improve raceway productivity; however the rate of photosynthesis does not increase beyond a PAR value of about 100-200 $\mu \mathrm{mol} . \mathrm{m}^{-2} . \mathrm{s}^{-1}$ [30]. 

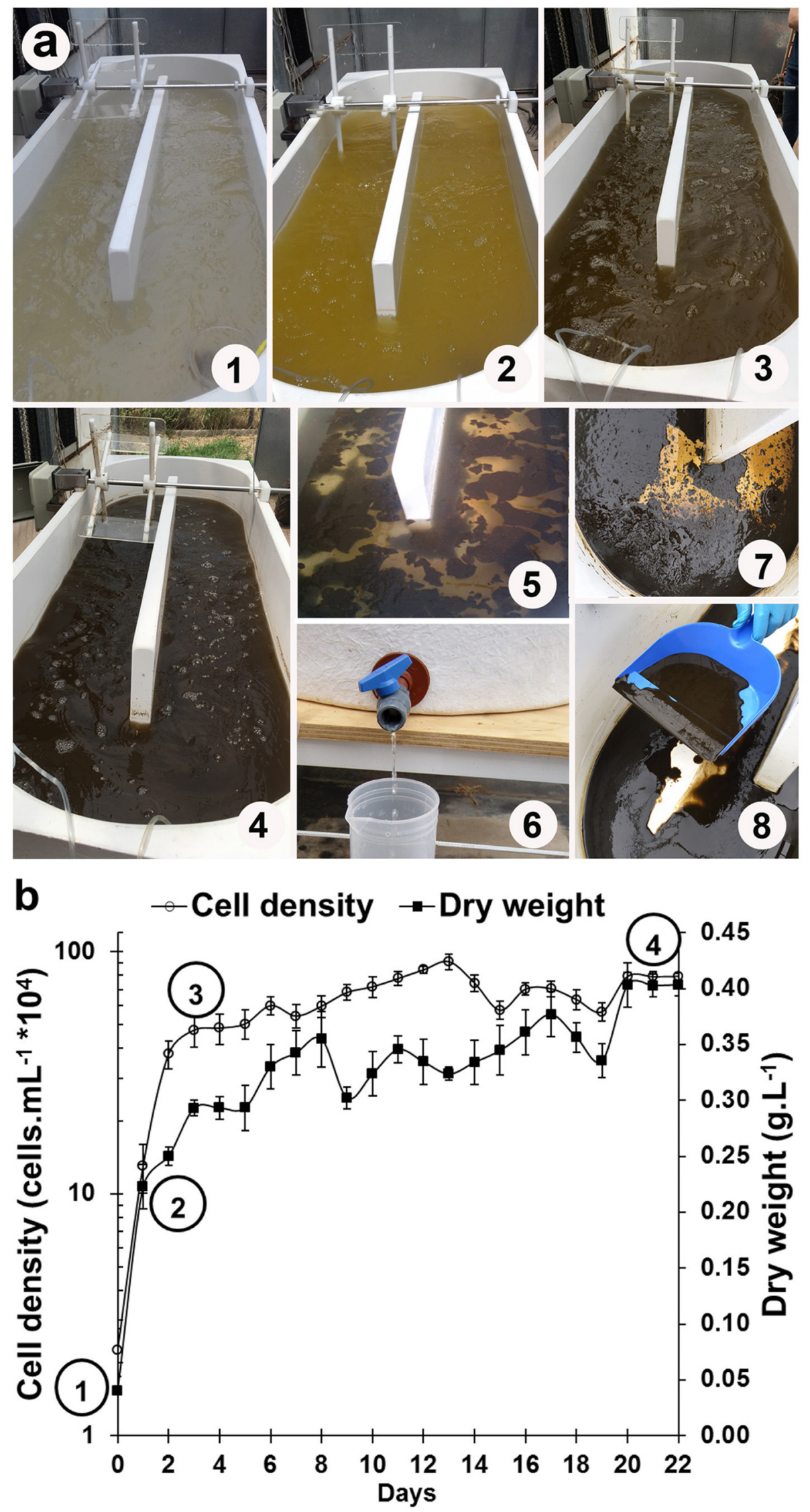

Fig. 2. H. coffeaeformis grown in a raceway pond throughout 22 days. (a) Several instances of H.coffeaeformis culture and harvesting: (1) day 0; (2) day 2; (3) day 4; (4) day 22; (5) biomass auto-flocculated with supernatant; (6) supernatant separation by a tap; (7) biofilm on the bottom without supernatant; (8) harvesting pellet by scraping. (b) Cell density and dry weight kinetics (inserted numbers match with the Fig. 2a ones). Data are expressed as mean \pm standard deviation (SD), $n=3$. 
Several instances of H.coffeaeformis culture and harvesting in a raceway pond are shown in Fig. 2a.The cell density and dry weight (DW) kinetics of this species throughout 22 days of culture is presented in Fig. 2b (numbers 1-4 in Fig. 2a, belonging to different growth stages, match with Fig. $2 \mathrm{~b}$ numbers). The exponential-growth phase ocurred from day 0 (Fig. 2a-1) to day 2 (Fig. 2a-2), followed by a stationarygrowth phase from day 3 (Fig. 2a-3) to day 22 (Fig. 2a-4). The culture showed neither a lag phase nor a typical declination phase, an advantage at the production level. The specific growth rate $(\mu)$ was $2.03 \mathrm{day}^{-1}$, corresponding to a doubling time of $11.8 \mathrm{~h}$. The initial cell density was $22 \times 10^{3}$ cells. $\mathrm{mL}^{-1}$, reaching approximately one million cells. $\mathrm{mL}^{-1}$ at day 13 . The biomass concentration presented a six-fold increase up to 0.3 g.L $\mathrm{L}^{-1}$ during the exponential phase, with the maximum value of 0.43 g.L $\mathrm{L}^{-1}$ at the end of the experiment. Biomass productivity during the exponential phase was $0.128 \mathrm{~g} \cdot \mathrm{L}^{-1} \cdot \mathrm{d}^{-1}$ and the areal yield was $25.73 \mathrm{~g} \cdot \mathrm{m}^{-2} \cdot \mathrm{d}^{-1}$. One of the main goals of the current study was to evaluate the potential of fertilizer to maintain high biomass levels of $H$. coffeaeformis in a batch-cultivation system, as a strategy for stimulating the valuable metabolite production. For industrial purposes, culture media producing similar or higher biomass yields than conventional media (i.e. f/2 medium) signify a cost saving. The biomass yields obtained were higher than that reported in the literaure for the same strain grown in an indoor raceway pond with $f / 2$ medium and artificial light [11], while the areal yield was similar to that observed in Amphora sp. MUR258 grown in an artificial $2 \mathrm{f}$ medium-based outdoor raceway pond [31]. This non-conventional culture medium therefore represents a highly promising resource for both increasing the growth rate of $H$. coffeaeformis and lowering the cost of large-scale biomass production.

For harvesting, the paddle wheels were stopped at day 22 and after $4 \mathrm{~h}$ the biomass auto-flocculated, settling to the bottom (Fig. 2a-5), thereby allowing a separation of microalgal cells (pellet) from the culture medium. The supernatant was removed under a tap (Fig. 2a-6) and the pellet (Fig. 2a-7) was harvested by scraping (Fig. 2a-8). $H$. coffeaeformis is a benthic diatom that grows naturally attached to the bottom of the water column; however, it grew successfully suspended in the culture medium under the mixing condition tested. Furthermore, its biomass auto-flocculated in a very short time by interruption of paddle wheels, without the requirement of chemicals or flocculants. Harvesting biomass by auto-flocculation requires less energy in large-scale systems [32]. Thus, the natural behaviour of $H$. coffeaeformis represents an advantage for downstream processing in raceway ponds since its harvesting does not require external energy.

\subsection{Dissolved and intracelular nutrient kinetics}

The dissolved and internal nutrient kinetics were investigated to evaluate the effect that a non-conventional culture medium can have on both biomass production and the biochemical composition of $H$. coffeaeformis. For this, dissolved nutrient (nitrate, ammonium, phosphate and silicate), internal nitrate (internal- $\mathrm{NO}_{3}{ }^{-}$) and both Si:N and N:P ratio kinetics in the raceway pond are shown in Fig. 3. The culture medium presented dissolved ammonium and nitrate as $\mathrm{N}$ source. The $\mathrm{NH}_{4}{ }^{+}$level decreased 96\% (from $700 \mu \mathrm{M}$ ) during the exponential growth phase, and then remained at a threshold value of ca. $20 \mu \mathrm{M}$ throughout the remainder of the experiment (Fig. 3a). The $\mathrm{NO}_{3}{ }^{-}$level diminished 50\% (from $466 \mu \mathrm{M}$ ), during the exponential growth phase and then decreased considerably from day 8 to day 15 , reaching values close to the limiting value (average Ks [N] of $1.2 \mu \mathrm{M}$ [33]). It is important to note that in the presence of two nitrogen sources, $H$. coffeaeformis showed a selective uptake of ammonium, though this nutrient never reached limiting values. Normally, $\mathrm{NH}_{4}{ }^{+}$is preferentially taken up by diatoms if both nitrate and ammonium are available in abundance. Cells using $\mathrm{NO}_{3}{ }^{-}$must expend significant amounts of energy for reduction to $\mathrm{NH}_{4}{ }^{+}$[34]. From the perspective of large-scale biomass production, the selective uptake of $\mathrm{N}$ observed in $H$. coffeaeformis represents a nutritional strategy that ensures a reserve of dissolved nitrogen for an extended period, consequently guaranteeing a prolonged stationary phase. Furthermore, some diatom species have the capacity to store significant amounts of $\mathrm{NO}_{3}{ }^{-}$internally [35], thus creating an additional $\mathrm{N}$ stock to maintain cell growth. $\mathrm{H}$. coffeaeformis presented an internal $\mathrm{NO}_{3}{ }^{-}$pool that ranged from 0.2 pg.cell ${ }^{-1}$ to 1.15 pg.cell ${ }^{-1}$ (Fig. 3a). The $\mathrm{N}$ storage of $H$. coffeaeformis could therefore contribute to its growth under limiting values for external $\mathrm{N}$. Phosphate reached limiting values (average Ks [P] of $1.2 \mu \mathrm{M}$ [33]) from day 16 (Fig. 3b) and Si never reached limiting values (average Ks [Si] of $3.9 \mu \mathrm{M}$ [33]) (Fig. 3c).

The N:P and Si:N ratio kinetics are shown in Fig. 3d. The initial N:P and Si:N ratios were ca. 11 and ca. 1 , respectively, close to to the standard ratio of $16 \mathrm{Si}: 16 \mathrm{~N}: 1 \mathrm{P}$ ratios [2]. These ratios, reflected in the high value of $\mu\left(2.03 \mathrm{day}^{-1}\right)$, indicate a favourable nutrient-sufficient scenario for setting up a diatom biomass production process. In fact, significant $\mathrm{Si}$ consumption was observed until day $5(\mathrm{Si}: N=14)$ (Fig. 3d), indicating strong cell division and the formation of new valves in the daughter cells. However, the stationary phase started on day 3. This behaviour could be explained by the light limitation due to cell shading, which would not affect the incorporation of Si since the silicification process does not require concurrent photosynthesis [36]. In contrast, nitrogen metabolism is closely associated with carbon metabolism, and consequently with metabolite production [3]. Both $\mathrm{Si}: \mathrm{N}$ and N:P ratios showed stronger nitrate uptake than $\mathrm{Si}$ and $\mathrm{P}$ between days 5 and 13, indicating a phase of nitrogen-dependent metabolite production (e.g. proteins). In the late stationary phase, the $\mathrm{N}: \mathrm{P}$ ratio reached values $>100$ from day 17 to day 22, indicating a stronger uptake of $\mathrm{P}$ than $\mathrm{N}$. In addition, in this period the $\mathrm{PO}_{4}{ }^{3-}$ reached limiting values. While this scenario would appear to indicate stressful growth conditions, the availability of ammonium, intracellular nitrate, and silicate may partially explain the lack of a declining growth phase. The findings indicate that the proposed culture medium shows a suitable Si:N:P balance, allowing for sustained biomass production of this species throughout 22 days, guaranteeing the accumulation of high-value metabolites.

\subsection{Biochemical composition of $H$. coffeaeformis}

Protein, carbohydrate and lipid volumetric concentration (mg. $\mathrm{L}^{-1}$ ) and content (mg. $\mathrm{g}^{-1} \mathrm{DW}$ ) kinetics of $H$. coffeaeformis are shown in Fig. 4a and Fig. 4b, respectively. The culture showed a basal production (day 0) of $5.2 \mathrm{mg} . \mathrm{L}^{-1}, 10 \mathrm{mg} . \mathrm{L}^{-1}$ and $9 \mathrm{mg} . \mathrm{L}^{-1}$ of proteins, carbohidrates and lipids, respectively. Protein production increased 21 -fold up to $107.7 \mathrm{mg} . \mathrm{L}^{-1}$ on day $13(p<0.05)$ and then decreased to $60 \mathrm{mg} . \mathrm{L}^{-1}$ at day 22 . This increased protein production necessary for cell growth was favored by higher nitrogen concentrations; production decreased during the late stationary phase (from day 13) in line with the strong decrease in nitrate (Fig. 3a and Fig. 3d).

Lipid production increased 14-fold up to a maximum value of 125 mg. $\mathrm{L}^{-1}$ on day 22 ( $\mathrm{p}<0.05$ ), the maximum content being $310 \mathrm{mg} \cdot \mathrm{g}^{-1} \mathrm{DW}$ (Fig. 4). Lipid accumulation in diatoms is triggered by stress conditions. Previous studies on $H$. coffeaeformis in $\mathrm{f} / 2$ reported significant lipid values, in particular TAG, under conditions of depleted dissolved and internal $\mathrm{N}$, silicate and phosphate $[11,12]$. Although lipid content increased in the present study, $\mathrm{N}$ and Si availability did not reach the limiting levels needed to induce maximum lipid accumulation in $H$. coffeaeformis.

The fatty acid (FA) profile of total lipids (Table 1) on day 22 revealed that PUFAs were the dominant lipid class $(36 \%$ of total fatty acids) of the harvested biomass, the most abundant among these (24.1\%) being eicosapentaenoic acid (C20:5 $\omega-3$, EPA) followed by arachidonic acid (C20:4 $\omega-6$, ARA) (4.4\%). The PUFA percentage was higher than that found for this strain grown on a $f / 2$ medium-based indoor raceway pond under nutrient stress [11]. Both EPA and ARA are highly valuable to the aquaculture industry and at present, their main 

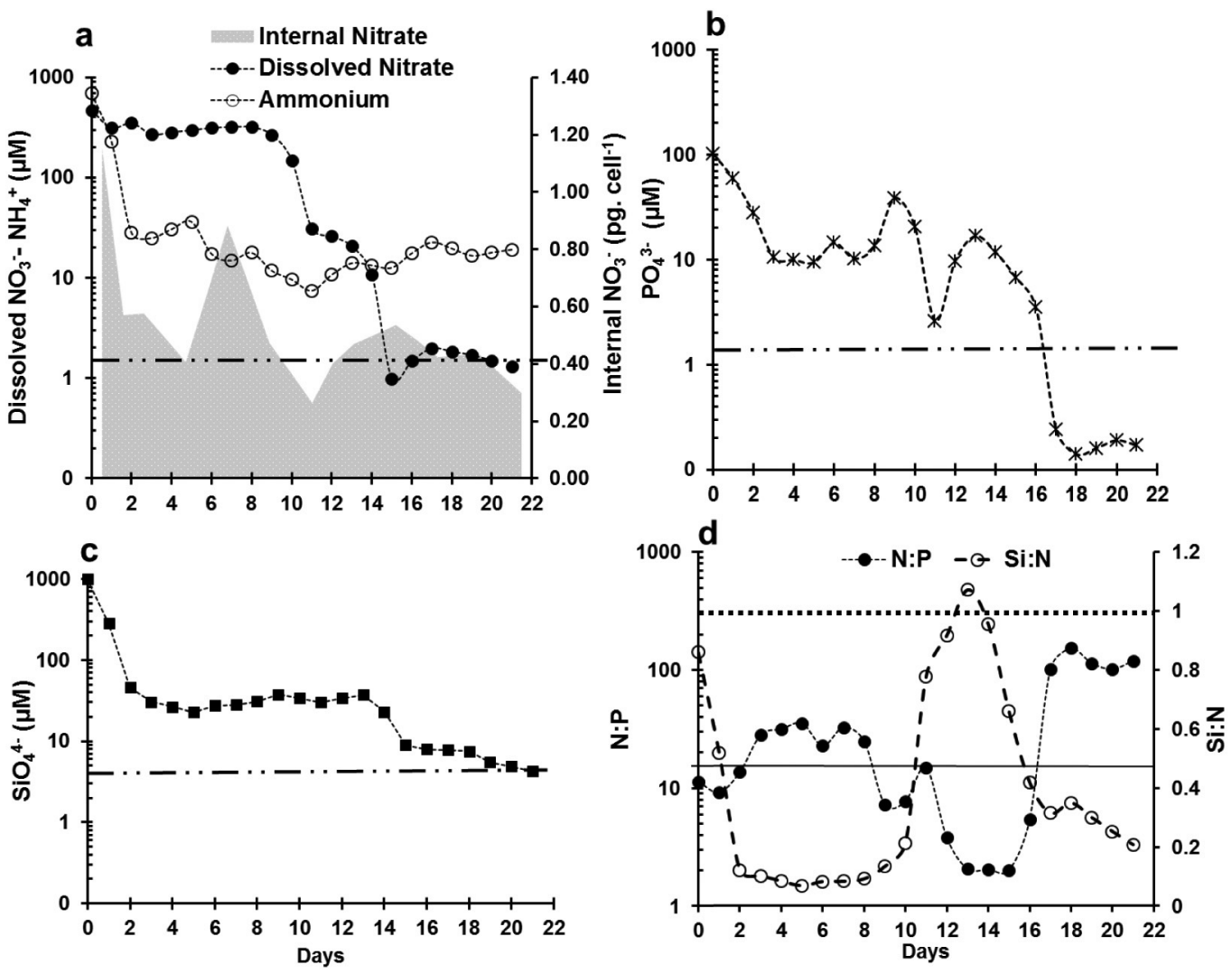

Fig. 3. $H$. coffeaeformis' nutrient kinetics in a raceway pond. (a) Dissolved nitrate and ammonium $(\mu \mathrm{M})$, and internal nitrate (pg.cell ${ }^{-1}$ ) kinetics; (b) dissolved phosphate $(\mu \mathrm{M})$ kinetics; (c) dissolved silicate $(\mu \mathrm{M})$ kinetics; (d) $\mathrm{Si}: \mathrm{N}: \mathrm{P}$ ratio kinetics. Data are expressed as mean, $\mathrm{n}=3$. Average limiting values of nutrients for diatom growth $(N<1.6 \mu \mathrm{M} ; P<1.2 \mu \mathrm{M}$; $\mathrm{Si}<3.9 \mu \mathrm{M})$ according to Sarthou et al. [33] are shown in Figs. a, b and c (dashed line). Non-limiting ratios are shown in Fig. $\mathrm{d}$ as $\mathrm{N}: \mathrm{P} \sim 16$ (straight line) and Si:N 1 (dotted line) according to Redfield/Brzezinski ratios of $16 \mathrm{Si}: 16 \mathrm{~N}: 1 \mathrm{P}$.

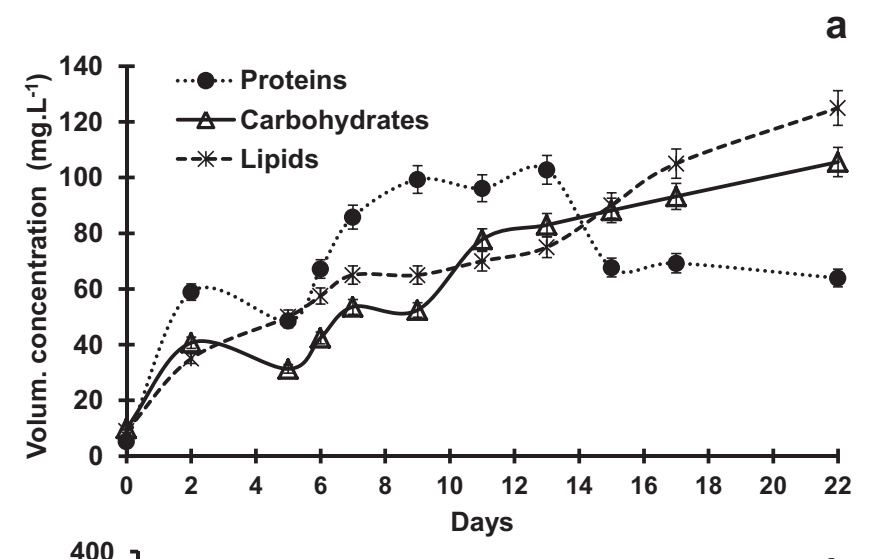

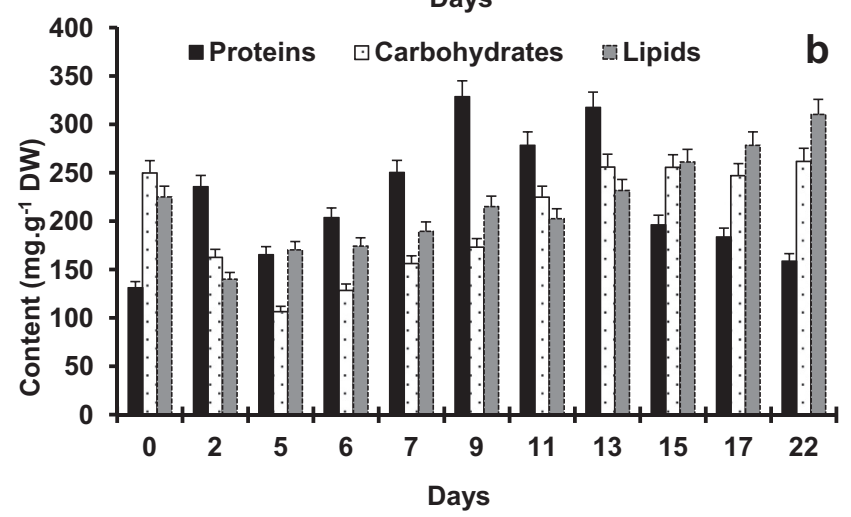

Fig. 4. H. coffeaeformis' valuable metabolites throughout 22 days of culture. (a) Kinetics of protein, carbohydrate and lipid volumetric concentration (mg. $\mathrm{L}^{-1}$ ). (b) Kinetics of protein, carbohydrate and lipid content (mg.g ${ }^{-1} \mathrm{DW}$ ). Data are expressed as mean $\pm \mathrm{SD}, \mathrm{n}=3$.
Table 1

Main fatty acids (\% of total fatty acids) from H.coffeaeformis' biomass on day 22; SFA: saturated fatty acids; MUFA: monounsaturated fatty acids; PUFA: polyunsaturated fatty acids. Data are expressed as mean $\pm \mathrm{SD}, n=4$.

\begin{tabular}{|c|c|}
\hline Main FAMEs & $\%$ of total lipids \\
\hline C14:0 (miristic) & $9.3 \pm 0.39$ \\
\hline C16:0 (palmitic) & $16.8 \pm 1.72$ \\
\hline C18:0 (stearic) & $0.3 \pm 0.08$ \\
\hline C16:1 (palmitoleic) & $25.9 \pm 1.16$ \\
\hline C18:1 $\omega-9$ (oleic) & $6.4 \pm 0.18$ \\
\hline C18:2 $\omega-6 c$ (linoleic) & $2.7 \pm 0.10$ \\
\hline C18:3 $\omega-3$ (linolenic) (ALA) & $1.3 \pm 0.07$ \\
\hline C20:4 $\omega-6$ (ARA) & $4.4 \pm 0.64$ \\
\hline C20:5 $\omega-3$ (EPA) & $24.1 \pm 0.78$ \\
\hline $\mathrm{C} 22: 6 \omega-3$ (DHA) & $0.7 \pm 0.02$ \\
\hline $\mathrm{C} 20: 2 \omega-6$ & $2.8 \pm 0.13$ \\
\hline$\Sigma$ SFA & $26.4 \pm 0.70$ \\
\hline$\Sigma$ MUFA & $32.3 \pm 0.96$ \\
\hline$\Sigma$ PUFA & $36 \pm 0.45$ \\
\hline
\end{tabular}

commercial source is from fish oils [37]. Microalgal growth rate optimization has been indicated as the best way to improve EPA yields and consequently to produce cost-competitive microalgae [15]. The use of Bayfolan $^{\circledR}$ fertilizer proved adequate for improving $H$. coffeaeformis growth and increasing its PUFA yield. Monounsaturated fatty acid (MUFA) reached 32\%, palmitoleic acid (C16:1) being the most abundant $(\sim 26 \%)$, followed by oleic (C18:1 $\omega-9)$ acid $(6.4 \%)$. According to the fatty acid profile, the $\omega-6: 3$ ratio of 0.4 was well below the suggested dietary $\omega-6: 3$ ratios (1:1 to $4: 1)$ [38]. This strain could therefore be particularly suitable for products designed to balance diets with excess $\omega-6$.

Carbohydrate production increased 10.5 -fold up to 105.9 mg.L ${ }^{-1}$ on day 22 ( $p<0.05$ ), when total carbohydrate content was $250 \mathrm{mg} \cdot \mathrm{g}^{-1} \mathrm{DW}$ (Fig. 4). Hot water extraction from cells yielded a 
Table 2

Composition of monosaccharide (mol \%) produced by methylation and acid hydrolysis of the W100 extract from $H$. coffeaeformis. Data are expressed as media $\pm \mathrm{SD}, \mathrm{n}=3$.

\begin{tabular}{lll}
\hline Monosaccharide $^{\mathrm{a}}$ & Deduced glycosidic linkage & W100-m \\
\hline 2,3,4,6-Me $\mathrm{Mlc}$ & Terminal & $14.0 \pm 1.6$ \\
$2,4,6-\mathrm{Me}_{3} \mathrm{Glc}$ & 3-linked & $73.4 \pm 0.8$ \\
4,6-- $\mathrm{Me}_{2} \mathrm{Glc}$ & 3-linked & $3.3 \pm 0.9$ \\
2-substituted & 3-linked & $4.9 \pm 0.8$ \\
$\mathrm{Glc}$ & 6-substituted & $4.4 \pm 0.3$ \\
\hline
\end{tabular}

a $2,4-\mathrm{Me}_{2} \mathrm{Glc}=$ 1,3,5,6-tetra-O-acetyl-2,4-di-O-methylglucitol; 4,6$\mathbf{M e}_{2}$ Glc $=$ 1,2,3,5-tetra- $O$-acetyl-4,6-di-O-methylglucitol; 2,4,6$\mathbf{M e}_{3} \mathrm{Glc}=$ 1,3,5-tri-O-acetyl-2,4,6- tri-O-methylglucitol; 2,3,4,6$\mathbf{M e}_{4}$ Glc $=$ 1,5-di-O-acetyl-2,3,4,6-tetra-O-methylglucitol.

product (W100) composed of monosacharides ( $\mathrm{mol} \%$ ), with glucose as the main component ( $94.4 \pm 0.3 \mathrm{~mol} \%, n=3$ ) and smaller amounts of rhamnossa $(1.7 \pm 0.5 \mathrm{~mol} \%, \mathrm{n}=3)$ and fucosa $2.4 \pm 0.6 \mathrm{~mol} \%$, $\mathrm{n}=3$ ). Mannose and glactose presented trace values $(<1 \mathrm{~mol} \%)$. Methylation analysis of W100 (W100-m) indicated the presence of a $(1 \rightarrow 3$ )-linked glucan with branching in C2 and C6 (Table 2). The ratio of tetramethylated terminal glucose residues $(14.0 \%)$ to the rest of the glucose units $(86.0 \%)$ showed that the glucan backbone was substituted every six glucose residues. The presence of a $(1 \rightarrow 3)$ - $\beta$-D-linked glucan suggests that this glucan derived from intracellular chrysolaminarin, as pointed out by Chiovitti et al. [39]. Chrysolaminarin from H. coffeaeformis presented branching in $\mathrm{C} 2$ and $\mathrm{C} 6$ as reported for analogous polymers in other diatom species [25,39,40]. A degree of branching $(D B)$ of 0.16 for the stored glucan of $H$. coffeaeformis was estimated from methylation analysis [25]. A wide range of $D B$, from 0.015 to 0.39 , has been reported $[7,25,39]$. Chrysolaminarin in diatoms is the primary carbon storage sink when nutrients are still available, whereas lipids, particularly TAG, predominate during high nutrient starvation [3]. In the present study, the chrysolaminarin content was $114 \mathrm{mg} \cdot \mathrm{g}^{-1}$ DW on day 22, representing $46 \%$ of total carbohydrate content.

The ${ }^{13} \mathrm{CNMR}$ spectrum of W100 showed distinct glucose-derived signals at $103.65,73.23,86.61,68.83,76.74$, and $61.28 \mathrm{ppm}$ assigned to C1, C3, C5, C2, C4, and C6, respectively (Table 3). To gain further insight into the derivatization reactions, $1 \mathrm{H}$ and $1 \mathrm{H}-13 \mathrm{C}$ HSQC NMR studies were performed. Substitution at the 6- position may be inferred from the $1 \mathrm{H}-13 \mathrm{C}$ HSQC results (Table 3$)$. The $\mathrm{C} 1 / \mathrm{H} 1$ of $\beta-(1 \rightarrow 6)$ was found at 104.24/4.37. Xia et al. [7] reported a similar structure in Odontella aurita, which presented a $\beta$-D- $(1 \rightarrow 3)$ (main chain) and $\beta$-D$(1 \rightarrow 6)$ (branch chain)-linked glucan. These authors revealed that this chrysolaminarin presented strong antioxidant activity. The $\beta$-glucans (especially $\beta-1,3 / 1,6$-glucans) have also been introduced as additives to improve the health and performance in marine ranching of fish, shrimp and gastropods [41].

Table 3

${ }^{1} \mathrm{H}-{ }^{13} \mathrm{C}$ HSQC NMR spectral assignment of the W100 extract from H. coffeaeformis.

\begin{tabular}{ll}
\hline Position & Chemical shifts ${ }^{13} \mathrm{C} /{ }^{1} \mathrm{H}(\mathrm{ppm})$ \\
\hline$\beta-(1 \rightarrow 3)^{\mathrm{a}}$ & \\
$\mathrm{C} 1 / \mathrm{H} 1$ & $103.65 / 4.51$ \\
$\mathrm{C} 2 / \mathrm{H} 2$ & $73.23 / 3.28$ \\
$\mathrm{C} 3 / \mathrm{H} 3$ & $86.61 / 3.47$ \\
$\mathrm{C} 4 / \mathrm{H} 4$ & $68.83 / 3.21$ \\
$\mathrm{C} 5 / \mathrm{H} 5$ & $76.74 / 3.25$ \\
$\mathrm{C} 6 / \mathrm{H} 6$ & $61.28 / 3.69,3.43$ \\
\hline
\end{tabular}

a The $\mathrm{C} 1 / \mathrm{H} 1$ of $\beta-(1 \rightarrow 6)$ was found at $104.24 / 4.37$.
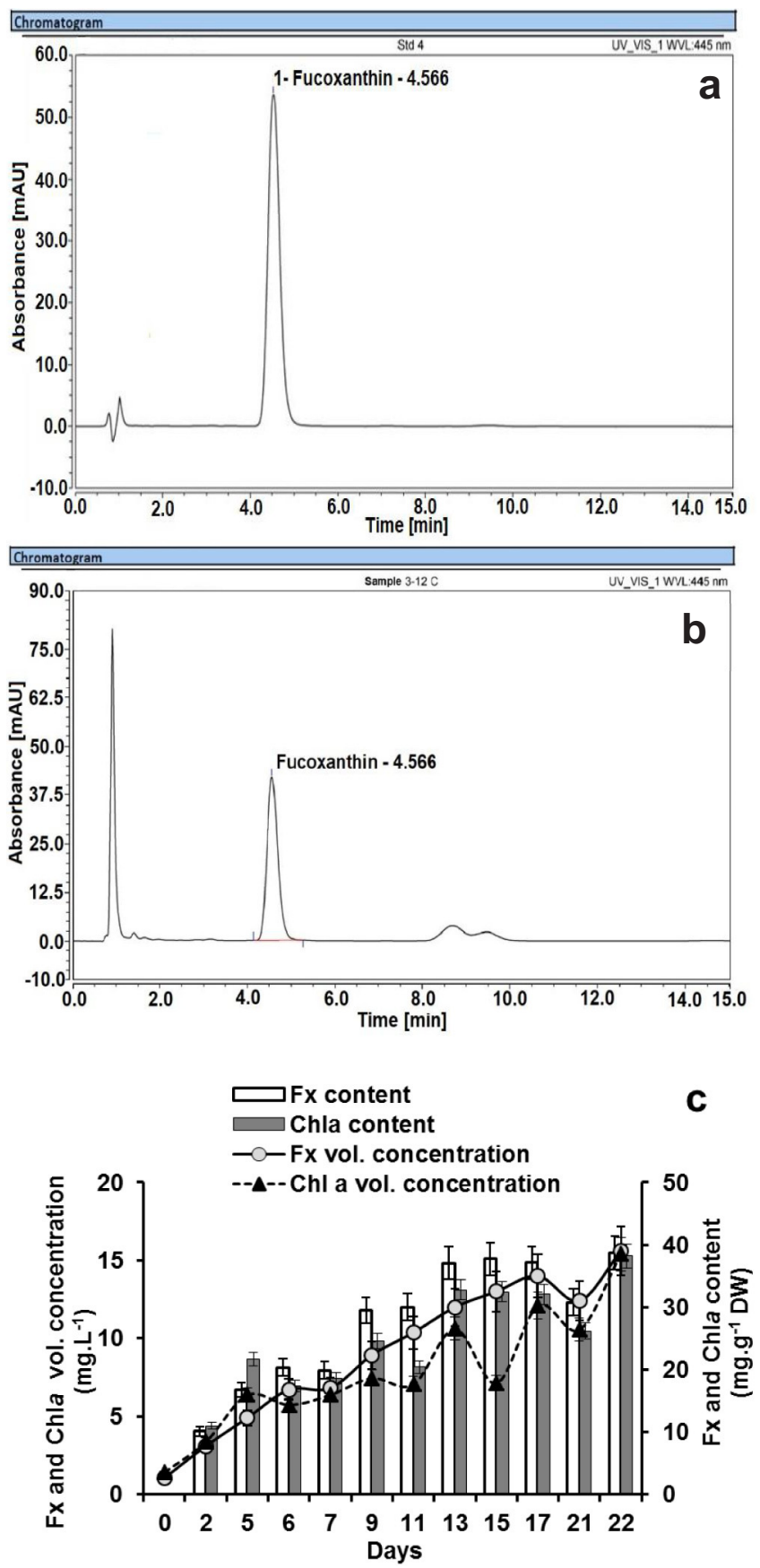

Fig. 5. H. coffeaeformis' pigments. (a) HPLC chromatogram of fucoxanthin (Fx) standard; (b) HPLC chromatogram of a crude extract; (c) Fx and Chl a volumetric concentration (mg. $\mathrm{L}^{-1}$ ) and content (mg.g $\left.{ }^{-1} \mathrm{DW}\right)$ kinetics. Data are expressed as mean \pm relative standard deviation (RSD), $n=3$. RSD was $2.1 \%$ according to HPLC analysis.

\subsubsection{Fucoxanthin and chlorophyll a}

Fucoxanthin (Fx), chlorophyll (Chl) $a$, Chl $c$ and an apoprotein constitute the main light-harvesting fucoxanthin and chlorophyll $\mathrm{a} / \mathrm{c}$ complex of brown macroalgae, haptophytes and diatoms. This complex transfers the absorbed energy to the Chl $a$-reaction centre, which participates directly in photosynthesis [6]. Fx is the most important carotenoid produced by diatoms, and has been reported to be a strong antioxidant metabolite [6]. In the present study, the Fx volumetric concentration (mg.L ${ }^{-1}$ ) of $H$. coffeaeformis was quantified by HPLC. Fx peaks from algal extracts were assigned by comparing their retention time with that of pure standard. The HPLC chromatogram of Fx 
standard is shown in Fig. 5a, with a peak retention time of 4.566 min; Fig. 5b shows an Fx peak from an ethanolic extract with a retention time of $4.566 \mathrm{~min}$. The Chl $a$ volumetric concentration $\left(\mathrm{mg} . \mathrm{L}^{-1}\right.$ ) in the same $H$. coffeaeformis crude extracts was quantified by UV-Vis spectroscopy. The volumetric concentration (mg. $\mathrm{L}^{-1}$ ) and content (mg.g $\mathrm{g}^{-1}$ DW) kinetics of Fx and Chl $a$ in $H$. coffeaeformis culture calculated from available HPLC and UV-Vis data are shown in Fig. 5c. Chl $a$ and Fx production increased throughout the experience up to $15.4 \mathrm{mg} . \mathrm{L}^{-1}$ and $15.6 \mathrm{mg} . \mathrm{L}^{-1}$ on day 22 , respectively; while the highest concentrations of Chl $a\left(\sim 26-38 \mathrm{mg} \cdot \mathrm{g}^{-1} \mathrm{DW}\right)$ and Fx $\left(\sim 30-38 \mathrm{mg} \cdot \mathrm{g}^{-1} \mathrm{DW}\right)$ were found from day 13 to day 22, respectively. Chl $a$ and Fx production and content showed a significant increase between day 0 and day 22 $(p<0.05)$. The simultaneous increase of Chl $a$ and Fx throughout the culture may be related to their similar physiological response to light and nutrient conditions. Fx content of $H$. coffeaeformis was higher than that reported for the related genus Amphora sp. $\left(1.21 \pm 0.18 \mathrm{mg} \cdot \mathrm{g}^{-1}\right.$ of DW) [16], matched favorably with the Fx content of Odontella aurita, a high-yielding diatom ( $>20 \mathrm{mg} \cdot \mathrm{g}^{-1}$ of DW) [6], and was at least thirty times higher than in brown macroalgae, the main commercial source of this pigment (e.g. 0.87 mg.g ${ }^{-1}$ DW) [26]. Fucoxanthin content varies according to species and strains of the same species, and is affected by culture conditions such as biomass productivity [16], light intensity [42], nitrogen concentration and/or source and salinity [16]. For example, the supply of both nitrate and light promoted Fx accumulation in Odontella aurita [6] and Cyclotella cryptica [42]. High biomass productivity was also necessary to ensure high Fx production in diatoms [16]. In the present study, Fx production reached its maximum value in synchrony with maximum biomass production. It is important to note that neither silica nor nitrogen was found in growth-limiting concentrations during this period. The cells had an important intracellular nitrate reserve and Chl $a$ showed no sign of a significant decline, suggesting that the culture remained active. On the other hand, the increase in salinity did not affect growth and may have favored Fx accumulation as has been proven in Amphora sp. and Phaeodactylum tricornutum $[43,44]$.

Finally, the biochemical composition of $H$. coffeaeformis biomass harvested on day 22 presented the following content (\% DW): 15\% proteins, 31\% total lipids rich in $\omega-3$ PUFA, $26 \%$ carbohydrates (11.96\% chrysolaminarin), $3.86 \%$ fucoxanthin and $3.81 \%$ chlorophyll $a$. The remaining content would include cell walls or frustules, which represent a significant fraction of $H$. coffeaeformis biomass $(\sim 20-25 \%$ DW), and present potential industrial applications [12]. Simultaneous accumulation of high-value metabolites was obtained under moderate $\mathrm{N}$ and Si limitation and $\mathrm{P}$ starvation, although continuous nutrient starvation could uncouple this relationship. This nutritional scenario must therefore be taken into account in programing the synchronized production of these valuable-biomolecules from $H$. coffeaeformis.

\section{Conclusions}

Value-added biocompound production is an attractive strategy that can efficiently contribute to the economic sustainability of the microalgal market. However, the scale of microalgal biomass production and harvesting costs are the major factors affecting economic investment in facility scale-up. In the present study, the optimal nutrient balance of the culture medium in combination with nutritional strategies (i.e. intracellular $\mathrm{NO}_{3}{ }^{-}$store; selective N-uptake) and salinity tolerance of $H$. coffeaeformis, represents a useful approach to guarantee both sustained biomass production and simultaneous accumulation of EPA, chrysolaminarin and fucoxanthin. The levels of these metabolites were relatively higher than those found in commercially used feedstocks. In addition, a cost-effective and environmental friendly bioprocess at prepilot scale has been established. In particular: a) the high $H$. coffeaeformis growth rate in a raceway pond indicates the optimum operational conditions and robustness of the species; b) the use of fertilizer $\left(\right.$ Bayfolan $^{\circledast}$ )-enriched seawater represents a cost-effective culture medium; and c) the auto-flocculation capacity of this strain contributes to economic harvesting. The present findings open the way for further progress toward the profitable and safe exploitation of H.coffeaeformis for biotechnological purposes (e.g. novel aquafeed additives, and/or biorefinery focusing on high-value compounds). Moreover, the global scarcity of fresh water and conventional high-value feedstocks justifies the search for alternative sources, in particular those of marine origin.

\section{CRediT authorship contribution statement}

Cecilia A. Popovich: Conceptualization, Investigation, Formal analysis, Writing - original draft, Writing - review \& editing, Funding acquisition. María B. Faraoni: Formal analysis. Alejandra Sequeira: Formal analysis. Yasmín Daglio: Formal analysis. Lucas A. Martín: Conceptualization, Formal analysis. Ana M. Martínez: Formal analysis. María C. Damiani: Formal analysis. María C. Matulewicz: Formal analysis, Funding acquisition. Patricia I. Leonardi: Conceptualization, Writing - original draft, Writing - review \& editing, Funding acquisition.

\section{Declaration of competing interest}

The authors declare that they have no known competing financial interests or personal relationships that could have appeared to influence the work reported in this paper.

\section{Acknowledgments}

This research was supported by grants from Comisión de Investigaciones Científicas de la Provincia de Buenos Aires (CIC) (Resolución $\mathrm{N}^{\circ}$ 801/18) to CAP, Agencia Nacional de Promoción Científica y Tecnológica (PICT 2015-0800), Consejo Nacional de Investigaciones Científicas y Técnicas de la República Argentina (CONICET, PIP 112-2015 01-00510), Universidad Nacional del Sur (PGI 24/B246) to PIL and Universidad de Buenos Aires (UBACYT 2018-2021 GC20020170100292BA) to MCM. The technical assistance by Jorge Oyola is acknowledged. CAP and MBF are Research Members of CIC. LAM, MCM and PIL are Research Members of CONICET.

\section{Statement of informed consent, human/animal rights}

No conflicts, informed consent, or human or animal rights are applicable to this study.

\section{References}

[1] N. Simon, A.L. Cras, E. Foulon, R. Lemée, Diversity and evolution of marine phytoplankton, Comptes Rendus - Biol 332 (2009) 159-170, https://doi.org/10.1016/j. crvi.2008.09.009.

[2] L.C. Gilpin, K. Davidson, E. Roberts, The influence of changes in nitrogen: silicon ratios on diatom growth dynamics, J. Sea Res. 51 (2004) 21-35, https://doi.org/10 1016/j.seares.2003.05.005.

[3] T. Obata, A.R. Fernie, A. Nunes-Nesi, The central carbon and energy metabolism of marine diatoms, Metabolites 3 (2013) 325-346, https://doi.org/10.3390/ metabo3020325.

[4] J.K. Wang, M. Seibert, Prospects for commercial production of diatoms, Biotechnol. Biofuels. 10 (2017) 1-13, https://doi.org/10.1186/s13068-017-0699-y.

[5] M. Mishra, A.P. Arukha, T. Bashir, D. Yadav, G.B.K.S. Prasad, All new faces of diatoms: potential source of nanomaterials and beyond, Front. Microbiol. 8 (2017) 1239, https://doi.org/10.3389/fmicb.2017.01239.

[6] S. Xia, K. Wang, L. Wan, A. Li, O. Hu, C. Zhang, Production, characterization, and antioxidant activity of fucoxanthin from the marine diatom Odontella aurita, Mar. Drugs. 11 (2013) 2667-2681, https://doi.org/10.3390/md11072667.

[7] S. Xia, B. Gao, A. Li, J. Xiong, Z. Ao, C. Zhang, Preliminary characterization, antioxidant properties and production of chrysolaminarin from marine diatom Odontella aurita, Mar. Drugs. 12 (2014) 4883-4897, https://doi.org/10.3390/ md12094883.

[8] W. Zhang, F. Wang, B. Gao, L. Huang, C. Zhang, An integrated biorefinery process: stepwise extraction of fucoxanthin, eicosapentaenoic acid and chrysolaminarin from the same Phaeodactylum tricornutum biomass, Algal Res. 32 (2018) 193-200, https://doi.org/10.1016/j.algal.2018.04.002.

[9] G.B. Bielsa, C.A. Popovich, M.C. Rodríguez, A.M. Martínez, L.A. Martín, 
M.C. Matulewicz, P.I. Leonardi, Simultaneous production assessment of triacylglycerols for biodiesel and exopolysaccharides as valuable co-products in Navicula cincta, Algal Res. 15 (2016) 120-128, https://doi.org/10.1016/j.algal.2016.01.013.

[10] C.A. Popovich, M. Pistonesi, P. Hegel, D. Constenla, L.A. Martín, G. Barnech Bielsa, M.C. Damiani, P.I. Leonardi, Unconventional alternative biofuels: quality assessment of biodiesel and its blends from marine diatom Navicula cincta, Algal Res. 39 (2019), https://doi.org/10.1016/j.algal.2019.101438.

[11] L.A. Martín, C.A. Popovich, A.M. Martinez, M.C. Damiani, P.I. Leonardi, Oil assessment of Halamphora coffeaeformis diatom growing in a hybrid two-stage system for biodiesel production, Renew. Energy 92 (2016) 127-135, https://doi.org/10. 1016/j.renene.2016.01.078.

[12] L.A. Martín, C.A. Popovich, A.M. Martínez, P.G. Scodelaro, M.C. Damiani, P.I. Leonardi, Hybrid two-stage culture of Halamphora coffeaeformis for biodiesel production: growth phases, nutritional stages and biorefinery approach, Renew. Energy 118 (2018) 984-992, https://doi.org/10.1016/j.renene.2017.10.086.

[13] M. Hayes, L. Bastiaens, L. Gouveia, S. Gkelis, H. Skomedal, K. Skjanes, P. Murray, M. García-Vaquero, M.I. Hosoglu, J. Dodd, D. Konstantinou, I. Safarik, G.C. Zittelli, V. Rimkus, V. del Pino, K. Muylaert, C. Edwards, M. Laake, J.G.L. da Silva, H. Pereira, J. Abelho, Microalgal bioactive compounds including protein, peptides, and pigments: applications, opportunities, and challenges during biorefinery processes, Nov. proteins food, Pharm. Agric. (2018) 239-255, https://doi.org/10. 1002/9781119385332.ch12.

[14] S. Leu, S. Boussiba, Advances in the production of high-value products by microalgae, Ind. Biotechnol. 10 (2014) 169-183, https://doi.org/10.1089/ind.2013. 0039 .

[15] M.S. Chauton, K.I. Reitan, N.H. Norsker, R. Tveterås, H.T. Kleivdal, A techno-economic analysis of industrial production of marine microalgae as a source of EPA and DHA-rich raw material for aquafeed: research challenges and possibilities, Aquaculture 436 (2015) 95-103, https://doi.org/10.1016/j.aquaculture.2014.10. 038.

[16] T. Ishika, N.R. Moheimani, P.A. Bahri, D.W. Laird, S. Blair, D. Parlevliet, Haloadapted microalgae for fucoxanthin production: effect of incremental increase in salinity, Algal Res. 28 (2017) 66-73, https://doi.org/10.1016/j.algal.2017.10.002.

[17] J.L. McLachlan, Growth media-marine, in: J.R. Stein (Ed.), Handb. Phycol. Methods Cult. Methods Growth Meas, Cambridge Univ. Press, Cambridge, 1973, pp. 26-47.

[18] J.D.H. Strickland, T.R. Parsons, A practical handbook of seawater analysis, second, Bull. Fish. Res. Bd, Canada (1972), https://doi.org/10.1007/978-1-4615-5439419.

[19] M.M. Bradford, A rapid and sensitive method for the quantitation of microgram quantities of protein utilizing the principle of protein-dye binding, Anal. Biochem. 72 (1976) 248-254.

[20] M. Dubois, K.A. Gilles, J.K. Hamilton, P.A. Rebers, F. Smith, Colorimetric method for determination of sugars and related substances, Anal. Chem. 28 (1956) 350-356.

[21] C.A. Popovich, C. Damiani, D. Constenla, A.M. Martínez, H. Freije, M. Giovanardi, S. Pancaldi, P.I. Leonardi, Neochloris oleoabundans grown in enriched natural seawater for biodiesel feedstock: evaluation of its growth and biochemical composition, Bioresour. Technol. 114 (2012) 287-293, https://doi.org/10.1016/j.biortech. 2012.02.121.

[22] C. Weldy, M. Huesemann, Lipid production by Dunaliella salina in batch culture: effects of nitrogen limitation and light intensity, J. Undergrad. Res. 7 (2007) 115-122, https://doi.org/10.1038/nrg2736.

[23] C.A. Popovich, C. Damiani, D. Constenla, P.I. Leonardi, Lipid quality of the diatoms Skeletonema costatum and Navicula gregaria from the South Atlantic Coast (Argentina): evaluation of its suitability as biodiesel feedstock, J. Appl. Phycol. 24 (2012) 1-10, https://doi.org/10.1007/s10811-010-9639-y.

[24] I. Ciucanu, F. Kerek, A simple and rapid method for the permethylation of carbohydrates, Carbohydr. Res. 131 (1984) 209-217, https://doi.org/10.1016/0008 6215(84)85242-8.

[25] Y. Daglio, M.L. Salum, M.C. Rodríguez, R. Erra-Balsells, M.C. Matulewicz, Characterization of nutrient status of Halamphora luciae (Bacillariophyceae) using matrix-assisted ultraviolet laser-desorption ionization time-of-flight mass spectrometry (MALDI-TOF MS), Eur. J. Phycol. 53 (2018) 422-432, https://doi.org/10. 1080/09670262.2018.1458336.

[26] S.M. Kim, Y.J. Jung, O.N. Kwon, K.H. Cha, B.H. Um, D. Chung, C.H. Pan, A potential commercial source of fucoxanthin extracted from the microalga Phaeodactylum tricornutum, Appl. Biochem. Biotechnol. 166 (2012) 1843-1855, https://doi.org/ 10.1007/s12010-012-9602-2.

[27] H. Wu, T. Li, G. Wang, S. Dai, H. He, W. Xiang, A comparative analysis of fatty acid composition and fucoxanthin content in six Phaeodactylum tricornutum strains from different origins, Chin. J. Oceanol. Limnol. 34 (2016) 391-398, https://doi.org/10. 1007/s00343-015-4325-1.

[28] E. Wang, C. Dong, R.F. Park, T.H. Roberts, Carotenoid pigments in rust fungi: extraction, separation, quantification and characterisation, Fungal Biol. Rev. 32 (2018) 166-180, https://doi.org/10.1016/j.fbr.2018.02.002.

[29] R.R. Bidigare, Analysis of algal chlorophylls and carotenoids, in: D.C. Hurd, D.W. Spencer (Eds.), Mar. Part. Anal. Charact, AGU, Washington, 1991, pp. 119-123, , https://doi.org/10.1029/GM063p0119.

[30] Y. Chisti, Large-scale production of algal biomass: raceway ponds, in: F. Bux, Y. Chisti (Eds.), Algae Biotechnol. Green Energy Technol, Springer International Publishing, 2016, pp. 21-40, , https://doi.org/10.1007/978-3-319-12334-9 2.

[31] I. Indrayani, N.R. Moheimani, M.A. Borowitzka, Long-term reliable culture of a halophilic diatom, Amphora sp. MUR258, in outdoor raceway ponds, J. Appl. Phycol. 31 (2019) 2771-2778, https://doi.org/10.1007/s10811-019-01803-y.

[32] F. Fasaei, J.H. Bitter, P.M. Slegers, A.J.B. van Boxtel, Techno-economic evaluation of microalgae harvesting and dewatering systems, Algal Res. 31 (2018) 347-362, https://doi.org/10.1016/j.algal.2017.11.038.

[33] G. Sarthou, K.R. Timmermans, S. Blain, P. Tréguer, Growth physiology and fate of diatoms in the ocean: a review, J. Sea Res. 53 (2005) 25-42, https://doi.org/10. 1016/j.seares.2004.01.007.

[34] P.M. Glibert, F.P. Wilkerson, R.C. Dugdale, J.A. Raven, C.L. Dupont, P.R. Leavitt, A.E. Parker, J.M. Burkholder, T.M. Kana, Pluses and minuses of ammonium and nitrate uptake and assimilation by phytoplankton and implications for productivity and community composition, with emphasis on nitrogen-enriched conditions, Limnol. Oceanogr. 61 (2016) 165-197, https://doi.org/10.1002/lno.10203.

[35] A. Kamp, P. Stief, L.A. Bristow, B. Thamdrup, R.N. Glud, Intracellular nitrate of marine diatoms as a driver of anaerobic nitrogen cycling in sinking aggregates, Front. Microbiol. 7 (2016), https://doi.org/10.3389/fmicb.2016.01669.

[36] V. Martin-Jézéquel, M. Hildebrand, M.A. Brzezinski, Silicon metabolism in diatoms: implications for growth, J. Phycol. 36 (2000) 821-840, https://doi.org/10.1046/j. 1529-8817.2000.00019.x.

[37] M. Sprague, M.B. Betancor, D.R. Tocher, Microbial and genetically engineered oils as replacements for fish oil in aquaculture feeds, Biotechnol. Lett. 39 (2017) 1599-1609, https://doi.org/10.1007/s10529-017-2402-6.

[38] A.P. Simopoulos, The importance of the ratio of omega-6/omega-3 essential fatty acids, Biomed. Pharmacother. 56 (2002) 365-379, https://doi.org/10.1016/S07533322(02)00253-6.

[39] A. Chiovitti, P. Molino, S.A. Crawford, R. Teng, T. Spurck, R. Wetherbee, The glucans extracted with warm water from diatoms are mainly derived from intracellular chrysolaminaran and not extracellular polysaccharides, Eur. J. Phycol. 39 (2004) 117-128, https://doi.org/10.1080/0967026042000201885.

[40] M.J. McConville, A. Bacic, A.E. Clarke, Structural studies of chrysolaminaran from the ice diatom Stauroneis amphioxys (Gregory), Carbohydr. Res. 153 (1986) 330-333, https://doi.org/10.1016/S0008-6215(00)90276-3.

[41] Y. Daglio, H. Sacristán, M. Ansaldo, M.C. Rodríguez, Benthic diatoms from potter cove, 25 de Mayo (King George) Island, Antarctica: mucilage and glucan storage as a C-source for limpets, Polar Sci 15 (2018) 39-48, https://doi.org/10.1016/j.polar. 2018.01.004.

[42] B. Guo, B. Liu, B. Yang, P. Sun, X. Lu, J. Liu, F. Chen, Screening of diatom strains and characterization of Cyclotella cryptica as a potential fucoxanthin producer, Mar. Drugs. 14 (2016), https://doi.org/10.3390/md14070125.

[43] T. Ishika, D.W. Laird, P.A. Bahri, N.R. Moheimani, Co-cultivation and stepwise cultivation of Chaetoceros muelleri and Amphora sp. for fucoxanthin production under gradual salinity increase, J. Appl. Phycol. 31 (2019) 1535-1544, https://doi. org/10.1007/s10811-018-1718-5.

[44] M.M.A. Nur, W. Muizelaar, P. Boelen, A.G.J. Buma, Environmental and nutrient conditions influence fucoxanthin productivity of the marine diatom Phaeodactylum tricornutum grown on palm oil mill effluent, J. Appl. Phycol. 31 (2019) 111-122, https://doi.org/10.1007/s10811-018-1563-6. 